\title{
CÁSINA: UM DESEJO PICANTE ${ }^{1}$
}

Carol Martins da Rocha ${ }^{\star}$

Universidade Estadual de Campinas

\begin{abstract}
As usually occurs in Plautus' comedy, in Casina the search for pleasure is an important motif of the plot. However in this play pleasure is represented - whether figuratively, whether more directly - in a particular mood. Besides a very recurrent use of metaphors and images related to scents and flavoring, there are notorious much more explicit (and not so commonly found in Plautine texts) mentions to the erotic desire and sexual intercourse. Evincing the uarietas in which pleasure is referred to in Casina, this article aims to reflect on how such a representation affects the composition of the Plautine plot. In Casina some sexual references also contribute to allude to another kind of pleasure: the one that comes from theater, represented in this comedy by a play-within-a-play.
\end{abstract}

KEYWORDS: Plautus; comedy; Casina; sexual desire; metatheatre.

\footnotetext{
${ }^{1}$ Uma versão prévia deste artigo foi proferida na sessão de comunicações coordenadas "Plauto e a poética da uoluptas", durante o XVII Congresso Nacional de Estudos Clássicos [SBEC/ UFRN, Natal (RN), 2009], que teve como tema "A amizade e o prazer no mundo antigo". A comunicação e o texto divulgam parte dos resultados da pesquisa de mestrado Perfume de mulher. Riso feminino e poesia em "Cásina" (FAPESP, processo n. 07/57173-3) desenvolvida sob orientação da Profa. Dra. Isabella Tardin Cardoso (IEL-UNICAMP). Uma versão atualizada da dissertação como um todo está no prelo da Editora da UNICAMP (Plauto. Cásina. Introdução, tradução e notas de Carol Martins da Rocha).

^carolletras@yahoo.com.br
} 


\section{Introdução}

O m Cásina ${ }^{2}$ - tal como é comum na comédia de Tito Mácio Plauto (séc. III-II a.C.) - a busca pelo prazer é notoriamente um motivo determinante para a progressão do enredo. A julgar pelas peças transmitidas, o público plautino estaria familiarizado com histórias em que uma personagem (normalmente um jovem, adulescens, mas há variações, como em Anfitrião e o final de Báquides), para obter os favores de sua namorada (em busca do prazer erótico, portanto), aceita a ajuda de um escravo enganador (seruus callidus). Também a procura pelos prazeres da mesa estimula o comportamento de determinadas personagens, como os parasitas, chegando, excepcionalmente, a constituir o centro da ação em boa parte da peça Estico. ${ }^{3}$

$\mathrm{Na}$ peça que apreciamos, a busca pelo prazer amoroso se manifesta de modo bastante contundente nas ações do velho Lisidamo, um senex amator, ${ }^{4}$ que contará com a cumplicidade de seu vizinho Alcésimo. ${ }^{5} \mathrm{O}$ desejo do senex amator pela escrava Cásina faz com que os dois velhos tramem juntos um plano para que o desejo de Lisidamo seja realizado.

\footnotetext{
${ }^{2}$ A peça foi composta, segundo estudiosos modernos, por volta de 184 a.C ou 185 (a última data coincidindo com o suposto ano da morte do dramaturgo); a data é especulada para a composição de Cásina sobretudo a partir de uma suposta alusão (v. 976ss.) à lei contrária às cerimônias de culto ao deus Baco (senatus consultus de bachanalibus), promulgada em 186 a.C. (cf. Plautus. Casina. Edited by W. T. MacCary and M. M. Willcock. Cambridge: University Press, 1976, p. 11). Cabe lembrar que as tentativas de datação das comédias plautinas são apenas hipotéticas (baseadas ora em incertas alusões a fatos históricos romanos, ora associadas de modo duvidoso a critérios estilísticos, como a quantidade de "árias", os cantica). Exceções são as peças Estico e Psêudolo, que chegaram aos dias atuais com suas notas de produção, indicando a data em que teriam sido apresentadas (200 a.C. e 191 a.C., respectivamente). Para uma lista completa da (polêmica) cronologia aventada, cf. Paratore, E. História da literatura latina. Lisboa: Calouste Gulbenkian, 1983, p. 43-44.

${ }^{3}$ Cf. Plauto. Estico. Introdução, tradução e notas de Isabella Tardin Cardoso. Campinas: UNICAMP, 2006.

${ }^{4}$ Sobre senes amatores na comédia plautina, conferir o item Senes de nossa supracitada dissertação e Rocha, C. M. Lisidamo, de "Cásina”: um velho apaixonado entre os "senes amatores" da comédia plautina. Anais do SETA. Campinas, vol. III, p. 132-143, 2008.

${ }^{5}$ No verso 515, Lisidamo afirma que vai colocar a amizade de Alcésimo à prova (Nunc amici/ anne inimici sis imago, Alcesime, $<515>$ Mihi sciam; nunc specimen specitur, nunc certamen cernitur. - v. 515-516).
} 
Em reação a essa busca, Mírrina e Cleóstrata, as duas matronas desta comédia, se aproximam: ${ }^{6}$ assim, em conjunto com os escravos, ambas preparam a emboscada contra o velho libidinoso.

Interessante é destacar que, nesta peça, a procura pelo prazer que, como referimos, é parte das convenções cômicas da palliata - não é apenas um pano de fundo para o desenrolar dos acontecimentos: ela é tematizada, como gostaríamos de mostrar, de modo surpreendente. O motivo poético do prazer derivado da alimentação surge, por exemplo, já em passagens que se referem a odores e temperos (v. 217-228...): no entanto, essas se mostram, claramente, referências metafóricas também ao prazer sexual. Mas isso não impede que haja cenas com menções mais explícitas a este tipo de prazer (v. 132-140; v. 723-758...). Nesse sentido, na trama, há, ainda, diversas brincadeiras envolvendo, inclusive, termos que aludem aos órgãos sexuais em si (v. 907-926; v. 928-930...) recurso, ademais, não tão recorrente na comédia de Plauto.?

Este artigo pretende evidenciar a uarietas com que o prazer é, pois, referido em Cásina, bem como refletir sobre os possíveis efeitos de uma tal representação do tema. Nossa impressão é de que tais efeitos podem ser observados em dois níveis: tanto no ambiente das personagens plautinas quanto, ao envolver ironia dramática e "peça dentro da peça", em relação ao público. Assim, a seguir nos concentraremos em observar o modo como o tema do prazer erótico vai sendo apresentado, por diferentes perspectivas, às personagens $\mathrm{e}$ espectadores plautinos.

\footnotetext{
${ }^{6}$ G. Chiarini (Plauto. Casina. Introduzione, traduzione e note a cura di Gioachino Chiarini. Roma: Carocci, 1998, p. 80) afirma que Mírrina é a amiga (amicam,v. 203) com a qual Cleóstrata está pronta a dividir tudo, desde sentimentos (v. 180-181) a pensamentos (v. 184-185).

${ }^{7}$ Diferentemente do que já existe na comédia de Aristófanes, cf. Henderson, J. The maculate muse. Obscene language in Attic comedy. New York/ Oxford: University Press, 1991./ cf. ainda Cardoso, I. T. Introdução à "Lisístrata” de Aristófanes. In: Aristófanes. Lisístrata. Tradução de A. M. C. Pompeu, introdução de I. T. Cardoso. São Paulo: Hedra, 2010, p. 9-38. Cabe dizer que carecemos de um estudo sobre a linguagem erótica em Plauto que nos permita, por exemplo, verificar a frequência e efeitos da alusão aos órgãos sexuais na comédia plautina como um todo. Embora, também quanto ao teor erótico, a linguagem de Plauto seja considerada mais vívida do que a de Terêncio, conforme B. A. Taladoire (Essai sur le comique de Plaute. Monaco: Les Éditions de l'Imprimerie Nationale de Monaco, 1957) pondera, raramente seu estilo é mais elaborado e menos direto do que se imagina.
} 


\section{Cásina - perfume de mulher}

A ligação entre os aromas e temperos e as relações amorosas é indicada em Cásina logo nos nomes de várias das personagens da peça, segundo apontam diversos estudiosos. Suspeita-se, por exemplo, que o nome da vizinha e amiga da esposa do velho Lisidamo, em latim Myrrhina (Mírrina), derive de myrtus (murta, espécie de arbusto) ou myrrha (mirra, espécie de perfume, incenso). ${ }^{8}$ Plínio, o Velho (23/ 24-79 d.C.), afirma, na obra História Natural (Nat. Hist. XIV 92ss.), que, na época de Plauto, os romanos teriam apreciado um vinho fortemente aromatizado à base de mirra, chamado de murrina; donde se cogita uma possível associação entre o nome da personagem e, no caso, uma bebida perfumada. ${ }^{9}$ Já o nome da escrava da matrona Cleóstrata, Pardalisca, seria um diminutivo de pardalis, "panterinha". Aponta-se, ainda, uma associação possível com o termo pardalium, que segundo o Oxford Latin Dictionary $(O L D)$, seria mais um tipo de perfume. ${ }^{10}$ No entanto, é de se ponderar que a relação do termo pardalis com um aroma seria menos direta, já que se teria que retomar, primeiramente, o sentido de leopardo, e só então surgiria a associação com a crença de que o hálito do animal teria um aroma exótico. ${ }^{11}$

De todo modo, tais especulações sobre o valor dos referidos nomes como speaking names, i.e. nomes com significado importante para

\footnotetext{
${ }^{8}$ Cf. Franko, G. Imagery and names in Plautus' "Casina". The Classical Journal. v. XCV, n. 1, p. 10, oct.-nov., 1999./W. T. MacCary e M. M. Willcock (op. cit., p. 95) apontam apenas a relação com myrtus.

${ }^{9}$ Cf. Chiarini, op. cit., p. 26./ Poderíamos mencionar ainda que, dentre os nomes das personagens plautinas, apenas duas apresentam, em sua formação, a desinência grega -ino, ambos no feminino: Casina e Myrrhina. O fato de ambas as personagens fazerem parte da mesma peça Cásina não parece ser irrefletido: ao fim da comédia, saberemos que Cásina é, na verdade, filha de Mírrina (Chiarini, op. cit., p. 25).

${ }^{10} \mathrm{Cf}$. OLD: "Pardalium": a kind of perfum, leopard - or panter - scent.

${ }^{11}$ Chiarini (op. cit., 1998) afirma que o nome Pardalisca (tomado como diminutivo de pardalis) poderia ser associado tanto ao odor característico do animal, usado para atrair a presa que em seguida é capturada, quanto aos ritos báquicos, já que a pantera era um animal típico do cortejo de Dioniso. Para o editor italiano, ambas as associações têm referentes no enredo da peça: a menção aos ritos báquicos faria alusão ao final da comédia (sobretudo aos versos 979ss.) e a menção ao odor da pantera remeteria ao motivo do perfume inebriante que encanta Lisidamo.
} 
sua caracterização na peça, ${ }^{12}$ foram certamente estimuladas por uma associação mais segura, pois que mencionada no texto plautino: a jovem e atraente escrava, que dá nome à peça ${ }^{13}$ (e que, embora não apareça em cena, é o pivô dos quiproquós do enredo), tem sem dúvida um "nome eloquente" e sugestivo. Isso porque, como já se apontou, em latim casina se refere ao substantivo comum casia, "canela", ou "o perfume feito da canela". ${ }^{14}$ De fato, constatamos que, no texto da peça, a relação entre o referido nome próprio e tal especiaria pode ser subentendida principalmente em duas passagens, que apresentamos a seguir:

Lysidamus: Omnibus rebus fego amorem credo et nitoribus nitidis ${ }^{15}$ anteuenire, nec potis quicquam commemorari, quod plus salis plusque leporis thodie habeat. Cocos equidem nimis demiror, qui utuntur condimentis, eos eo condimento uno $<$ non $>$ utier, omnibus quod praestat.

Nam ubi amor condimentum inerit, cuiuis placituram $<$ escam $>$ credo. Neque salsum neque suaue esse potest quicquam, ubi amor non admiscetur:

\footnotetext{
${ }^{12}$ Para uma discussão quanto à pertinência de speaking names em Estico, cf. Plauto, op. cit., 2006b, p. 32-39.

${ }^{13}$ A. S. Gratwick (cf. Plautus. Menaechmi. Edited by A. S. Gratwick. Cambridge: University Press, 1993, p. 6) adverte que não se pode dizer que os títulos das comédias plautinas remanescentes provenham de fato da época em que Plauto as compusera, nem mesmo que, caso provenham, os títulos outrora tivessem a mesma função (de resumir a ideia central da obra) hoje a eles atribuída. Todavia, ainda que o título Cásina seja acréscimo pós-plautino, não se pode negar a coerência de tal referência a perfume de mulher com alguns aspectos da comédia em estudo, tal qual transmitida.

${ }^{14} \mathrm{O} O L D$, no sentido $1 \mathrm{a}$, abona a probabilidade de casia nomear árvore do gênero Cinnamomum (cf. Plin. Nat. Hist. 10, 4; 12, 95); no sentido 1b, aponta o uso do extrato de tal árvore em medicina e em perfumaria. No segundo sentido, cita-se a passagem plautina, Cur. 101.

${ }^{15}$ Nitoribus nitidis (v. 217): Chiarini (op. cit., p. 86) afirma que a introdução do tema dos nitores [nitor seria o brilho obtido pelo uso de óleos, unguentos - no caso de Lisidamo, certamente de algum produto para os cabelos (cf. v. 237)] indica já a "transformação" da paixão de Lisidamo por Cásina em paixão pelos "perfumes" (evidente que Cásina continuará encantando com seu já citado "perfume de canela").
} 
Fel quod amarumst, id mel faciet: ${ }^{16}$ hominem ex tristi lepidum ${ }^{17}$ et lenem (grifos nossos). ${ }^{18}$

Nos versos acima, Lisidamo, o velho apaixonado por aquela escrava, fala do amor como tempero (condimentum, v. 219) da vida, comentando como sua adição é capaz de lhe conferir sal (cf. salsum, v. 222) ou doçura (cf. suaue, v. 222).

Mais adiante, outra personagem usa o verbo obolere ("exalar cheiro de", "recender a") ao se referir jocosamente ao escravo que se disfarçara da ansiada Cásina: "Já se sente o cheiro de Cásino de longe!" (Pardalisca: ${ }^{\dagger}$ Iam oboluit Casinus procul ${ }^{\dagger}$ v. 814): ${ }^{19}$ evidente associação entre o nome da personagem epônima e a etimologia que acima referimos.

É curioso, pois, notar que, em Cásina, de maneira viva, o desejo de Lisidamo, motor inicial da ação, se apresenta por meio de uma conjugação entre ao menos dois tipos de prazeres convencionais à palliata: os da cama e os da mesa. Passemos agora a outros tipos de representação do prazer erótico nessa peça.

\footnotetext{
${ }^{16}$ Chiarini (op. cit., p. 88) chama a atenção para a repetição de uma oposição envolvendo termos frequentes no linguajar erótico plautino: fel e mel (cf. Cist. 69; Poen. 394; Truc. 179).

${ }^{17}$ Lepidum (v. 226): o termo lepidus é muito recorrente em Cásina (sendo registrado também nos versos 476, 480, 491, 559, 726, 748, 771, 773, 927, 935, 1008 da peça). No entanto, é difícil manter, ao longo da versão, uma tradução única para um vocábulo que cobre um número tão variado de sentidos.

${ }^{18} \mathrm{O}$ texto latino de Casina que citamos é o da edição de A. Ernout. (cf. Plaute. Bacchides; Captiui; Casina. Edição e tradução de Alfred Ernout. Paris: Les Belles Lettres, 1996. Tomo II, v. 217-223): "Lisidamo: Todas as coisas eu acredito que o amor supera, e até as mais brilhantes entre as brilhantes, e não é possível lembrar que possa existir hoje algo que tenha mais sabor e mais graça. Muito me admira que os cozinheiros, que fazem uso de temperos, não usem justamente esse tempero, que vale mais que todos. $<220>$ Pois onde o amor estiver, como um tempero, acredito que $<$ a comida $>$ a todos agradará. E nada, em que não se misturar amor, pode ter sal ou doçura. O fel, que é amargo, ele há de tornar mel: de um homem amargurado, fará um charmoso e tranquilo" (tradução nossa).

${ }^{19}$ A interpretação dos manuscritos é problemática nesta passagem. Discute-se a que personagem essa fala seria atribuída. Schoell remete-a a flautistas que estariam em cena, Lindsay a Calino, e Leo afirma que a fala pode ser de Calino ou Pardalisca (cf. Ernout, op. cit., p. 208./ MacCary; Willcock, op. cit., p. 186-187).
} 


\section{Amor de verdade}

Em alguns versos de Cásina, encontramos referências amenas às relações amorosas e seus prazeres, como, por exemplo, nesta passagem da primeira cena do primeiro ato:

OL. Concludere in fenestram firmiter,

Vnde auscultare possis, quom ego illam ausculer

Quom mihi illa dicet: 'mi animule ${ }^{20} \mathrm{mi}$ Olympio,

Mea uita, mea mellilla, mea festiuitas

Sine tuos ocellos deosculer, uoluptas mea,

Sine, amabo, te $<\mathrm{d}>$ amari, meus festus dies

Meus pullus passer, mea columba, mi lepus',

Quom mi haec dicentur dicta, tum tu, furcifer,

Quasi mus in medio parieti uorsabere. ${ }^{21}$

Nessa passagem, o escravo Olímpio (suposto do velho Lisidamo) narra a Calino (escravo aliado de Cleóstrata) a futura noite de amor que haveria de ter com a escrava Cásina. Na imaginação do caseiro Olímpio, Calino assistirá às carícias que ele, Olímpio, receberia de Cásina. Esta, por sua vez, não só haveria de chamar o caseiro de "meu amorzinho, meu Olímpio, minha vida, meu docinho, minha alegria, meu dia de festa, meu pássaro preferido, minha pomba, meu coelho" (termos que, em latim, têm notório sentido erótico), ${ }^{22}$ como também aludiria a carinhos físicos, ao pedir para beijar-lhe os olhos e permitir que ela o ame.

Porém, nem tudo na peça Cásina é imaginação. Embora os espectadores não vejam propriamente cenas de cunho sexual no palco

\footnotetext{
${ }^{20}$ Animule: literalmente, "meu coraçãozinho" (a palavra animulus é diminutivo de animus, cf. OLD). Como lembram W. T. MacCary e M. M. Willcock (op. cit., p. 116), este e os outros nove nomes carinhosos pelos quais Cásina chamaria Olímpio na imaginação do escravo são exemplos de um recurso típico de Plauto, a exuberância linguística (linguistic exuberance).

${ }^{21}$ Casina, v. 132-140 - "Olímpio: Você será preso firmemente no vão da janela, de onde poderá ouvir enquanto eu a estiver beijando. Quando ela me disser: 'Meu amorzinho, meu Olímpio, minha vida, meu docinho, minha alegria, $\langle 135\rangle$ deixe eu beijar seus olhinhos, meu desejo: deixe, por favor, que eu seja amada por você, meu dia de festa, meu pássaro preferido, minha pomba, meu coelho'. Quando essas palavras me forem ditas, você, então, seu patife, vai ficar se revirando no vão da parede, feito um rato" (tradução nossa).
}

${ }^{22}$ Cf. Adams, N. The Latin sexual vocabulary. London: Duckworth, 1982. 
(recurso cabível para outro tipo de espetáculo em Roma, os mimos), ${ }^{23}$ há momentos que, mesmo sendo apenas narrados, apresentam situações amplamente erotizadas e até mesmo, como referimos no início deste texto, diversas brincadeiras que aludem aos órgãos sexuais em si.

Uma dessas passagens é compreendida nos versos a seguir, que ocorrem depois de transcorridos já mais de dois terços da ação. Ali, Olímpio conta à escrava Pardalisca o que teria acontecido no tão esperado encontro com Cásina - que, como os espectadores àquela altura já sabiam (desde o verso $769^{24}$ ), na verdade era um "Cásino", isto é, o escravo Calino disfarçado de noiva. O estabelecimento do texto no passo em questão apresenta várias lacunas, conforme os símbolos entre parênteses $(\star \star \star)$ indicam:

OL. Vbi intro hanc nouam nuptam deduxi, recta uia in conclaue abduxi./Sed tam [en] tenebrae ibi erant [tam]quam in puteo. Dum senex abest, $/<<$ Decumbe $>>$ inquam./ Conloco, fulcio, mollio, blandior,/Vt prior quam senex nup (lacuna) (...) Inlecebram stupri principio eam sauium posco (lacuna)/ Reppulit mihi manum/Neque enim dare sibi/ Sauium me siuit./ Enim iam ${ }^{\dagger}$ magis iam adpropero, $<890>$ / Magis iam libet in Casinam inruere;/Cupio illam operam seni surripere. ${ }^{25}$

Como se percebe, Olímpio conta, passo a passo, a sua tentativa de sedução: apesar de o escravo ter "ajeitado" a suposta "Cásina", tentado amolecer seu coração, as tentativas foram em vão. $\mathrm{O}$ escravo galanteador

\footnotetext{
${ }^{23} \mathrm{Cf}$. Beare, W. The Roman stage. A history of Roman drama at the time of republic. London: Methuen \& Co., 1964, p. 149-154.

${ }^{24}$ Elas duas, por outro lado, enfeitam no quarto o escudeiro, que vai ser dado, no lugar de Cásina, como esposa ao nosso caseiro [Illae autem in cubiculo armigerum exornant duae, quem dent pro Casina nuptum nostro uilico (v. 769-770)].

${ }^{25}$ Casina, v. 881-883/v. 887-892 - "Olímpio: Logo que conduzi a recém-casada lá pra dentro, levei-a direto para o quarto. Mas ali estava tão escuro quanto um poço. Enquanto o velho não estava, eu disse 'deite-se'. Eu a ajeito, acomodo-a, deixo-a mole, falo palavras doces, para que eu a tenha primeiro que o velho $(\star \star \star)(\ldots)$. Como preliminar, começo pedindo um beijo a ela $(\star \star \star \star)$ Ela me repeliu a mão e sequer permitiu que eu lhe desse um beijo. Mas agora, na verdade, eu tenho mais pressa ainda, $<890>$ quero ainda mais partir para cima de Cásina: desejo surrupiar do velho esta 'tarefa' (tradução nossa - O texto está corrompido entre os versos 884 e 887. É possível compreender o sentido geral do verso 884, pelo contexto da peça, mas não os seguintes, que também possuem lacunas)”.
} 
tenta então pedir um beijo: seria uma espécie de "preliminar". O termo latino empregado para designar o que nós traduzimos por "preliminar" é mais forte: stuprum (v. 887), que designa, de acordo com o $O L D$, uma "vergonha" ou "uma relação sexual ilícita, forçada ou não". ${ }^{26}$ Mas, se é assim, como justificar que uma personagem denomine deste modo, como ilícito, sua relação com aquela que seria, desde aquela noite, sua própria esposa? Ao que parece, com o termo a personagem acena ao público (que previa a existência de uma conspiração contra o velho, mas não sabia exatamente como o engano seria colocado em prática) que haveria algo errado nessa cena erótica. A denominação do ato de prazer como um struprum, ou seja, uma relação expressa como vergonhosa, serve aqui como um momento de ironia dramática, confiando ao público, ainda mais, um conhecimento superior ao de Olímpio (que nem do travestimento nem da existência de um plano sabia).

Segundo G. Chiarini, ${ }^{27}$ o recurso é semelhante (envolvendo ironia dramática e a representação de elementos relacionados ao prazer erótico) a uma outra referência presente na trama. Ao público, o escravo Calino é apresentado logo no prólogo como um armiger (ou seja, uma espécie de escudeiro) do filho de Lisidamo, Eutinico (v. 55) - este, como o velho pai, apaixonado por Cásina e, portanto, aliado de Cleóstrata versus Lisidamo. Ao longo da ação, entretanto, não há nenhuma indicação de que esse escravo realmente se comporte como tal: a própria personagem não faz menção alguma às suas funções de escudeiro, muito menos age como os demais escudeiros plautinos. ${ }^{28}$ Assim, afirma Chiarini, a nomeação do escravo como escudeiro, na verdade, abre a possibilidade

\footnotetext{
${ }^{26}$ Stupri principio (v. 887): lit. "como começo do ato sexual". Segundo Adams (op. cit., p. 200-201), o sentido original do termo stuprum era de "desgraça" [sentido atestado por Festo (cf. Adams, op. cit., p. 200)]. Entretanto, mais tarde o termo se torna específico e designa uma "desgraça sexual", ou seja, um ato sexual ilícito, seja uma relação adúltera ou uma violação forçada (segundo Adams, na época de Plauto o termo parece já ter este sentido). Ainda de acordo com o mesmo estudioso, o termo poderia designar tanto uma relação heterossexual quanto uma homossexual. Embora stupri não indique necessariamente uma relação forçada (sentido que o termo "estupro" toma em português atualmente), essa é a situação denotada na maior parte das vezes, segundo informa Adams (cf. Adams, op. cit., p. 200-201).

${ }^{27}$ Cf. Chiarini, op. cit., p. 19.

${ }^{28}$ Por exemplo, Tesprião da peça Epídico, que faz alusões concretas a seu passado belicoso, conta vantagem, recorre a expressões típicas do vocabulário militar (cf. Chiarini, 1998, p. 15-17).
} 
de, já de antemão, anunciar seu papel: enquanto defensor dos interesses do grupo contra Lisidamo, Calino, como veremos adiante, porta uma "espada" (gladium), ${ }^{29}$ uma grande "espada": nesse sentido bem concreto é que, para a trama, Calino se mostra, pois, um "escudeiro".

É interessante observar como as metáforas (stupri para relação sexual lícita e gladium para designar outro objeto...) envolvem aspectos relacionados ao sexo, e, por consequência, ao (apesar de frustrado) prazer sexual. Mas, como estamos numa comédia, nem todas as referências à frustração são levadas tão a sério. Continuando a narrativa de seu infortunado encontro amoroso, é jocoso o modo como Olímpio conta, com mais detalhes, à escrava Pardalisca seus primeiros contatos com o "corpo" supostamente pertencente à tão desejada "Cásina":

OL. Oh, erat maximum;/ (lacuna) haberet metui: id quaerere occepi (lacuna)/ Dum gladium quaero ne habeat, (lacuna) arripio (lacuna) capulum./Sed cum cogito, non habuit gladium: nam essetfrigidus. $<910>$ / PAR. Eloquere./ OL. At pudet./ PAR. Num radix ${ }^{30}$ fuit?/ OL. Non fuit./ PAR. Num cucumis?/ OL. Profecto hercle (lacuna) non fuit quicquam holerum./ Nisi quicquid erat, calamitas ${ }^{31}$ profecto attigerat numquam,/ Ita quicquid erat, grande erat. ${ }^{32}$ / PAR. Quid fit denique, edisserta./ <OL.> Ibi appello: '33 'Casina', inquam,/ 'Amabo, mea uxorcula, cur uirum tuum sic me spernis?/ Nimis tu quidem hercle immerito/ Meo mihi haec facis, quia mihi te expetiui'. $<920>/$ Illa haud uerbum facit, et saepit ueste id qui estis <mulieres >./ Vbi illum saltum uideo opsaeptum, rogo ut altero (lacuna) ${ }^{34}$ sinat ire./Volo, ut obuertam, cubitis im (lacuna) / Vllum muttit e (lacuna)/Surgo, ut in

\footnotetext{
${ }^{29}$ Gladium: na peça Cásina, o termo é enfaticamente repetido, referindo-se a vários elementos (registrado nos versos 307, 629, 660, 691, 706, 751, 909, 910).

${ }^{30}$ Radix (v. 911): o termo designa literalmente uma raiz. No entanto, preferimos traduzi-lo por "tubérculo" para evidenciar ainda mais as brincadeiras com vocábulos do âmbito alimentício.

${ }^{31}$ Calamitas (v. 913): segundo MacCary e Willcock (op. cit., p. 200), calamitas é o termo técnico para "praga numa colheita"; sendo assim, persiste o imaginário da agricultura.

${ }^{32}$ Grandis (v. 914): segundo MacCary e Willcock (op. cit., p. 200), Dousa, comentador de Plauto (Centurionatus siue Plautinarum explicationum libri IV. Leyden: 1587), afirma que o adjetivo é empregado regularmente para designar uma colheita "produtiva". ${ }^{33}$ Apello (v. 916): MacCary e Willcock (op. cit., p. 200) notam que o termo teria um sentido mais sensual explicado por Ulpiano (séc. II d. C.): tentar seduzir (try to seduce). No entanto, nenhum dos outros editores que consultamos adota essa sugestão.

${ }^{34}$ Segundo Adams (op. cit., p. 113) subentende-se aqui altero saltu, o equivalente à "outra passagem", i.e. o culus.
} 
eam in (lacuna) <925> / Atque illam in (lacuna) (...) Sauium (lacuna) / Ita quasi saetis labra mihi conpungit barba (lacuna) / Continuo in genua ut astiti (grifos nossos).

Como vemos, a passagem é repleta de metáforas que, na boca do escravo desconcertado, vão como que a contragosto delineando aquilo que os espectadores (e as mulheres que elaboraram o plano) já sabiam: ${ }^{36}$ Cásina é na verdade Calino disfarçado de noiva. Em um apelo cômico, Pardalisca explora todas as possibilidades de fazer com que o escravo procure, envergonhado, explicar como a tal Cásina poderia ter uma espada, que nem era fria.

Mas, observemos com atenção a passagem: temos, então, uma série de comparações, colocadas em forma de perguntas: seria o tal objeto uma espada (gladium, v. 909, 910) ou, quem sabe, um tubérculo (radix, v. 911), ou, por acaso, um pepino (cucumis, v. 912a)? Não, pois, no tocante à primeira hipótese, ele não era frio, e, no tocante às demais, segundo Olímpio, não se tratava de nenhum tipo de legume (holerum, v. $912 b)$.

A brincadeira metafórica continua no trecho da narrativa de Olímpio em que ele conta sua tentativa de, digamos, investir contra a "escrava". Ele teria tentado despir Cásina, mas em vão: a "escrava" "cobre com a veste aquilo que a faz mulher" (saepit ueste id qui estis <mulieres $>$, v. 921). Tal atitude incita ainda mais o desejo de Olímpio, que, ao ver a

\footnotetext{
${ }^{35}$ Casina, v. 907-926/v. 928-930 - "Olímpio: Ah, era muito grande: (lacuna) temi que ela tivesse: comecei a procurar $(\star \star \star)$. Enquanto me perguntava se ela não teria uma espada (gladium) ( $\star \star \star)$, agarrei o punho. Mas pensando bem, não era uma espada: pois seria fria. $<910>$ / Pardalisca: Continue./ Ol.: Mas eu tenho vergonha!/ Par.: Não era um tubérculo?/ Ol.: Não era./ Par. Nem um pepino?/ Ol. Por Hércules, certamente não era nenhum tipo de legume. O que quer fosse certamente nunca foi tocado por nenhuma praga. O que quer que fosse era grande./ Par. O que aconteceu afinal? Conte tudo tintim por tintim./ <Ol. > Aí eu chamo: 'Cásina' - e digo - 'por favor, minha esposinha, por que me despreza, a mim, seu marido, assim? Por Hércules, de fato, eu, que a desejei tanto, não mereço que você faça isso comigo'. $<920>$ Ela não diz uma palavra e cobre com a veste aquilo que a faz mulher. Quando vejo aquela selva bloqueada, peço que ela deixe-me enfiar na outra ... ( $\star \star$ $\star$ ). Quero ficar de cotovelos para me virar $(\star \star \star)$ Não dá um pio $(\star \star \star \star)$ Eu me levanto para nela $(\star \star \star)$ E nela $(\star \star \star)$ (...) Um beijo $(\star \star \star)$ Então uma barba como se fosse um porco-espinho me pinica os lábios ( $\star \star \star)$ " (tradução nossa).

${ }^{36}$ Como dissemos, a revelação sobre a verdadeira identidade da "noiva" já fora feita no verso 769.
} 
"selva" (saltum, v. 922) encoberta, procura atingir a outra "entrada" [altero (saltu), v. 922) de Cásina. O termo usado aqui para designar o órgão sexual feminino (saltum) pertence, segundo Adams, ${ }^{37}$ primariamente, ao campo semântico da agricultura e seu uso com o sentido metafórico é registrado apenas nesta passagem plautina ${ }^{38}$ (a brincadeira com o mesmo termo permanece na referência à outra "entrada" de Cásina; assim, o termo passa a designar o culus). Vemos, então, que o uso de termos metafóricos referentes aos órgãos sexuais é bastante recorrente nessa passagem da comédia Cásina.

Como sumário do exposto, vemos que, na peça plautina em estudo, são extremamente numerosas e variadas as imagens que, por meio de metáforas e comparações, remetem ao sexo, e, direta ou indiretamente, ao possível prazer erótico. Diferentes campos semânticos são evocados: o campo semântico dos aromas e da culinária (associáveis tanto aos significados dos nomes das mulheres - isso é certo ao menos no tocante ao nome da protagonista - quanto nas referências ao amor como tempero), o de cunho militar (na nomeação de Calino como armiger - ponto-chave para o jogo verbal que se desenvolve, mais para o final da peça, com a "espada" (gladium) de Cásina/Calino), o da agricultura (nas comparações entre os órgãos sexuais - masculinos: radix, cucumis, holerum; femininos: saltum, altero salto).

\section{O vocabulário do prazer e a peça/ engano dentro da peça}

Como breve conclusão, pensamos ser interessante considerar algumas funções das referências ao prazer sexual tal como empregadas na peça Cásina. Em primeiro lugar, vimos que a caracterização de uma personagem como armiger diz respeito não a um tipo convencional da

\footnotetext{
${ }^{37}$ Cf. Adams, op. cit., p. 84.

${ }^{38}$ Saltum (v. 922): num sentido geral, saltus designa uma passagem estreita através de uma floresta ou região montanhosa (cf. entrada 1 do $O L D$ ). Metaforicamente, o termo é usado para designar o órgão sexual feminino. Embora MacCary e Willcock (op. cit., p. 201) afirmem que o vocábulo seria usado comumente em seu sentido metafórico, o OLD não registra este uso do termo. Além disso, Adams (op. cit., p. 84) assevera que o termo saltus (que pertence, primariamente, ao campo semântico da agricultura) não é usado com o sentido metafórico em outras passagens, além dessa plautina. Mesmo com o uso restrito, a metáfora seria facilmente reconhecida, dado o largo uso, de forma geral, do simbolismo envolvendo termos da agricultura e os órgãos sexuais.
} 
palliata, mas se revela um instrumento para a referência a gladium, uma metáfora para o órgão sexual masculino: portanto, algo inicialmente apresentado ao público como um dado da peça passa a dizer respeito, efetivamente, a um recurso importante para o desenvolvimento da ação, o ludíbrio de Olímpio, planejado pelas mulheres dessa comédia. Essa função só é completamente desvelada ao público ao final, quando a plateia ouve a narração do travestimento de Calino na noite de núpcias de Olímpio.

Pode-se pensar que, no enredo, o travestimento gera, junto a esta personagem, impacto semelhante ao deslocamento de sentido do termo "escudeiro"/ "espada" junto ao público: ambos são elementos de uma peça (dentro da peça) pregada em Olímpio e em seu mestre.

Muito se comentou sobre a teatralização deste engano em Plauto, ${ }^{39}$ que o texto plautino faz questão de sublinhar em passagens como a seguinte, em que o autor do logro equivale a um poeta, o engano a um drama:

Myrrhina: Nec fallaciam astutiorem ullus fecit

Poeta atque ut haec est fabre facta ab nobis. ${ }^{40}$ (grifos nossos)

Mas queríamos destacar algo que, ao que parece, não se tem observado em Cásina: num primeiro nível, as metáforas agrícolas e alimentícias da narratio da cena de núpcias contribuem para caracterizar de modo engraçado a frustração do prazer sexual, num contexto em que a revelação da função metafórica do termo armiger serve para gerar uma divertida surpresa junto à plateia. Num segundo nível, pode-se perceber que, também por causa de um uso bem planejado das metáforas sexuais (somado a recursos metateatrais mais explícitos da comédia, como, por exemplo, os versos acima referidos), tal frustração da libido de Olímpio passa a equivaler, na perspectiva do público desta comédia, a uma representação da ilusão teatral: pois, ao perceber a "espada", a personagem percebe ao mesmo tempo o fato de ter sido alvo de uma encenação, de um engano teatralizado.

Enfim, Cásina é ou não é um desejo perigoso e picante?

\footnotetext{
${ }^{39}$ Cf. estudos de Petrone (Teatro antico e inganno. Finzioni plautine. Palermo: Palumbo Editore, 1983), Slater (Plautus in Performance. The theatre of the mind. Amsterdam: Harwood Academic Publishers, 2000) e Cardoso [Ars Plautina. Tese de doutorado inédita. São Paulo: FFLCH-USP, 2005./ Ilusão e Engano em Plauto. In: Cardoso, Z. A; Duarte, A. S. (Org.). Estudos sobre o teatro antigo. São Paulo: Alameda, 2010, p. 95-126].

${ }^{40}$ Casina, v. 860-861 - "Mírrina: Poeta algum compôs uma artimanha $<860>$ mais bem bolada que esta bolada por nós” (tradução nossa).
} 


\section{Referências}

ADAMS, N. The Latin sexual vocabulary. London: Duckworth, 1982.

ARISTÓFANES. Lisístrata. Trad. M. C. Pompeu, introdução de I. T. Cardoso. São Paulo: Hedra, 2010.

BEARE, W. The Roman stage. A history of Roman drama at the time of republic. London: Methuen \& Co., 1964.

CARDOSO, I. T. Ars Plautina. Tese de doutorado inédita. São Paulo: FFLCH-USP, 2005. . Ilusão e engano em Plauto. In: CARDOSO, Z. A; DUARTE, A. S. (Org.).

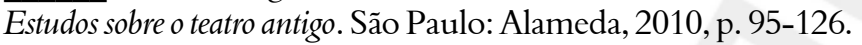
Introdução à "Lisístrata" de Aristófanes. In: ARISTÓFANES. Lisístrata. Trad. A. M. C. Pompeu, introdução de I. T. Cardoso. São Paulo: Hedra, 2010, p. 9-38. COSTA, L. N. Mesclas genéricas na 'tragicomédia' "Anfitrião” de Plauto. Dissertação de mestrado inédita. Campinas: IEL-UNICAMP, 2010.

GLARE, P. G. W. (Org.). Oxford Latin Dictionary. Oxford: Clarendon Press, 1982.

FRANKO, G. F. Imagery and names in Plautus' "Casina". The Classical Journal, v. XCV, n. 1, p. 1-17, oct.-nov., 1999.

HENDERSON, J. The maculate muse. Obscene language in Attic comedy. New York/ Oxford: University Press, 1991.

PARATORE, E. História da literatura latina. Lisboa: Calouste Gulbekian, 1983.

PETRONE, G. Teatro antico e inganno. Finzioni plautine. Palermo: Palumbo Editore, 1983.

PLAUTE. Bacchides; Captiui; Casina. Edição e tradução de Alfred Ernout. Paris: Les Belles Lettres, 1996. Tomo II.

Cásina. Introdução, tradução do latim e notas de Aires Pereira do Couto. Lisboa: Edições 70, 2006 a.

Casina. Introduzione, Traduzione e note a cura di Gioachino Chiarini. Roma: Carocci, 1998.

Casina. Edited by W. T. MacCary and M. M. Willcock. Cambridge: University Press, 1976.

. Estico. Introdução, tradução e notas de Isabella Tardin Cardoso. Campinas: UNICAMP, 2006b. Menaechmi. Edited by A. S. Gratwick. Cambridge: University Press, 1993.

ROCHA, C. M. Lisidamo, de "Cásina": um velho apaixonado entre os "senes amatores" da comédia plautina. Anais do SETA. Campinas, vol. III, p. 132-143, 2008.

. Perfume de mulher. Riso feminino e poesia em "Cásina". Dissertação de mestrado inédita. Campinas: IEL-UNICAMP, 2010.

SLATER, N. W. Plautus in performance. The theatre of the mind. Amsterdam: Harwood Academic Publishers, 2000.

TALADOIRE, B. A. Essai sur le comique de Plaute. Monaco: Les Éditions de l'Imprimerie Nationale de Monaco, 1957.

Recebimento contínuo - Aceite: 15 de maio de 2011 